\title{
Piezoresistive bond lines for timber construction monitoring-experimental scale-up
}

\section{Christoph Winkler ${ }^{1,2} \mathbb{D} \cdot$ Stefan Haase ${ }^{1,2} \cdot$ Ulrich Schwarz ${ }^{1,2} \cdot$ Markus Jahreis $^{1,2}$}

Received: 15 January 2021 / Accepted: 18 May 2021 / Published online: 24 June 2021

(C) The Author(s) 2021

\begin{abstract}
Several laboratory studies and experiments have demonstrated the usability of polymer films filled with electrically conductive filler as piezoresistive material. Applied to adhesives, the glue lines of wood products can achieve multifunctional-thus bonding and piezoresistive/strain sensing-properties. Based on critical load areas in timber constructions, upscaled test setups for simplified load situations were designed, especially with regard to a stress-free electrical contact. In a second step, another upscaling was done to small glulam beams. Based on an experimental test sequence, the piezoresistive reactions as well as the behaviour until failure were analysed. The results show in all cases that a piezoresistive reaction of the multifunctionally bonded specimens was measurable, giving a difference in the extent of relative change. Additionally, measured phenomena like inverse piezoresistive reactions, electrical resistance drift and the absence of a piezoresistive reaction were discussed, based on additional strain analysis by digital image correlation. A model of macroscopic and microscopic strains influencing the piezoresistive reaction of the electrically conductive bond line in wood was used to explain all experimental results. Finally, a first scale-up of piezoresistive bond lines from laboratory samples to glulam beams was possible and successful.
\end{abstract}

\section{Introduction}

Timber structures are particularly exposed to environmental influences and must therefore be preserved by constructive wood protection and monitored by inspection intervals. While constructive wood protection elongates the usability of the structure, inspection intervals help to prove the integrity of infrastructure, public or re-utilised buildings. From an economic viewpoint, the costs and time of

Christoph Winkler

christoph.winkler@hnee.de

1 University of Applied Sciences Eberswalde, Eberswalde, Germany

2 Hochschule für nachhaltige Entwicklung Eberswalde, Alfred-Möller-Straße 1, 16225 Eberswalde, Germany 
inspections are justified by alternative maintenance costs, protection of capital investment and assurance of safety of the inspected structures (Kasal and Tannert 2010). Due to decreasing costs of sensors and interpretation software, structural health monitoring (SHM) - the permanent integration of sensors into structures and assessing of their integrity by cyclic measurement-has become an important strategy to reduce the maintenance costs while keeping a high level of safety (Balageas et al. 2006).

In the last years, the currently available methods for assessing and monitoring timber structures non- or less destructively have been reviewed and it was shown that several sensors are usable and reliable for monitoring purposes (Koch et al. 2016; Kurz 2015; Kurz and Boller 2015; Tannert et al. 2010; Tannert and Müller 2010).

Nonetheless, the additional costs for integrating these sensors into timber structures are high due to the necessary highly specialised staff and the time-consuming installation. Usage of electrically conductive adhesives as sensory layers can help at this point. The integration of these multifunctional adhesives during the manufacturing of glulam beams, cross-laminated timber or other engineered wood products can help to decrease the production costs and integrate sensors at points inside the engineered product.

Research on adhesives with electrical conductive nanofillers (depending on the application and research area also called nanocomposites, ECA's, multifunctional adhesives, etc.) was mostly focussed on the application of cold bonding in electronic devices to replace soldering joints. Considerable investigations tried to overcome the decrease in bonding strength by the historically used silver filler with carbon allotropes like carbon nanotubes, graphene and carbon black (Han et al. 2019; Masaebi et al. 2018; Massoumi et al. 2015; Santamaria et al. 2013; Wehnert et al. 2014). Generally, electrically conductive adhesives consist of electrically conductive particles in an insulating polymeric matrix. They show as bond lines a piezoresistive effect, which generally describes a change in electrical resistance with strain. With increasing strain, the length and cross section of the electrically conductive polymer as well as the amount of conductive paths of the filler particles change.

In previous publications by the working group, this piezoresistive effect has been shown for small samples of adhesively bonded wood specimens from beech wood (Fagus sylvatica L.) under compression stress (Winkler et al. 2020b), under tensile and compression stresses in beams (Winkler and Schwarz 2016) as well as under pull-shear stress (Winkler and Schwarz 2016).

First of all, the later presentation of the results as positive or negative piezoresistive reaction (PR) per stress unit in this paper needs to be delimited from the scientifically defined piezoresistivity.

Piezoresistivity is typically described by the gauge factor (GF) and given by the fractional change of resistance per strain unit if the change is reversible. Mathematically described (Eq. 1), the fractional change in resistance $(\Delta R / R)$ of the measured material depends on the fractional change in volume resistivity $(\Delta \rho / \rho)$ as well as the strain $(\Delta \mathrm{l} / \mathrm{l})$ in direction of the resistance measurement and the Poisson's ratios $\nu_{1}$ and $\nu_{2}$ of the material in transverse directions to the resistance measurement (Chung 2020) 


$$
\frac{\Delta R}{R}=\frac{\Delta \rho}{\rho}+\frac{\Delta l}{l} *\left(1+v_{1}+v_{2}\right)
$$

Based on the general definition of tensile strain as positive and compressive strain as negative, the piezoresistivity/GF

$$
\mathbf{G F}=\frac{\Delta \mathbf{R}}{\mathbf{R}} / \frac{\Delta \mathbf{l}}{\mathbf{l}}
$$

becomes positive if the fractional change in resistance $(\Delta R / R)$ increases/decreases according to the strain $(\Delta \mathrm{l} / \mathrm{l})$. Thus, an increasing resistance under tensile strain as well as a decreasing resistance under compressive strain is defined as positive piezoresistivity. A reversed reaction gives a negative piezoresistivity. Finally, both definitions are only valid under the assumption that measuring direction of resistance and strain direction are aligned. Furthermore, shear strain and its resulting piezoresistivity are not defined for in-plane shearing of electrically conductive films. Theoretically, the signal at in-plane shear strain can be positive (from pull-shear-tests) or negative (from push-shear-tests) and the change in conductive paths along the electrically conductive particles will be independent of the direction; the piezoresistivity by this definition must be positive and at the same time negative. Therefore, the change in electrical resistance due to strain will be reported as PR, which in the following is defined positive for increasing resistance with applied strain and negative for decreasing resistance with strain.

Additionally, a real analysis of GF for adhesive bond lines in timber structures is only possible if the cross section of the bond line is constant, the parameters are known (thus, $\rho$ is calculable) and the change in the cross section can be measured during deformation (thus, the Poisson's ratio $v$ is calculable). It can be seen from Fig. 1 that even for laboratory specimens, it is difficult to calculate the cross section of the bond line within spruce (Fig. 1a). In other wood species the penetration into wood cells and vessels (Fig. 1b) is even higher; besides, one-component polyurethane (1C-PUR)-based adhesives show imperfection due to for example cavities from $\mathrm{CO}_{2}$-forming (Fig. 1c).

Therefore, due to the relationship of stress and strain, the PR's in adhesive bond lines in timber will be presented stress related, keeping in mind that scientifically piezoresistivity is strain related.

Other challenges come up, when piezoresistive bond lines are applied to timber structures. Due to its grain-oriented structure, timber exhibits a strong orthotropic elasticity and due to fibre- and density-based irregularities in the macroand microstructure also heterogeneity. Thus, the relation between strain and stress depends on the micro-, meso- and macrostructure (Oppel et al. 2016). Therefore, there are difficulties in detecting and isolating the values of stress and strain in detailed structures with strain gauges or in this case, multifunctional adhesive bond lines. For example, notches near the support of a bending beam enforce lateral tension stress to the timber/adhesive bond line. The result is a crack layer from the inner edge towards the beam. Moreover, the stress distribution shows a strong peak at the beginning and a steep decrease over the length (Franke et al. 


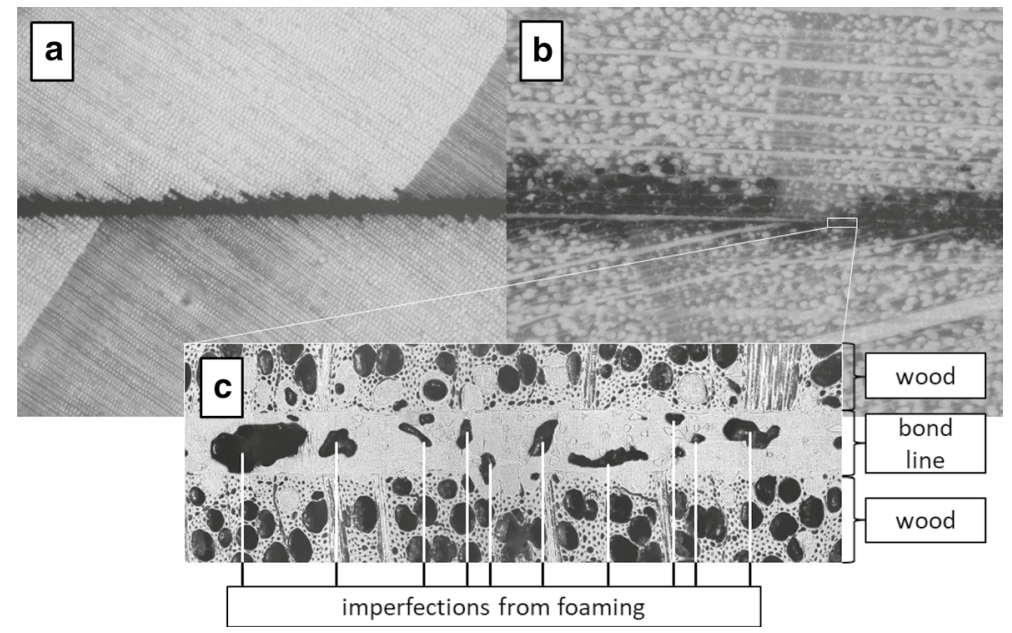

Fig. 1 Cross section of laboratory produced multifunctional bond lines in spruce a, beech $\mathbf{b}$ and a highly resolved image of the cross section of a multifunctional bond line from 1C-PUR $\mathbf{c}$ with marked imperfections

2007). On the other side, shear stresses also appear at those points, leading to several overlapping stresses.

These challenges are increasing with an upscaling of structural elements, raising the question of whether the PR in the previously investigated laboratory scaled specimens are applicable to glulam beams (Winkler et al. 2020b; Winkler and Schwarz 2014).

Therefore, the objective of the experiments was to determine the feasibility of the given multifunctional bond lines under load in real situations by a first scale-up of the laboratory tests. It should answer the question, whether the change in electrical resistance of the adhesive layer - the PR-can be used in glulam beams to detect stress. According to the theory, the working hypothesis was that the piezoresistivity can be transferred to glulam beams and different stresses can be distinguished by the direction and extent of PR.

\section{Materials and methods}

\section{Specimen design}

Specimens were first upscaled with regard to load situations, which often occur in glulam constructions or which are prone to critical overloading. Because of the three-dimensional behaviour of a material [see Mohr-Coulomb theory (Mang and Hofstetter 2013)], it is almost impossible to create single mode tests for isolated stresses. In particular, there are no shear tests without lateral stress at all. Even if the load and support are placed in one line, there are deviation forces, bending, compression and elongation. Furthermore, the stress along a bond line is not distributed 
equally. The geometry, basically the anchorage length, influences the stress distribution at the end of the bond line. There is a singularity at every end of a member or a change of material, which induces peaks in the stress distribution. With an increasing mounting length, the slenderness of the connection increases. Thus, the inhomogeneity of the stress distribution rises (Jahreis and Rautenstrauch 2016; Kästner et al. 2014). This is also comparable with the shear distribution inside a bending beam according to Filon 1903.

Thus, to investigate the PR of the multifunctional adhesive in shear mode, pushshear-tests were used, because of the low load capacity for lateral pull stress of timber.

Setups for longitudinal tension stress in tapered finger joints and transversal tension were adapted from standardised methods. In all designs, a stress-free electrical connection to the specimen as well as an electrochemically stable electrode was considered (see Fig. 2). Additional photographs with indicated features are available as online supplementary material.

The stress-free electrical connection was realised by recesses in the material or offsets between the two bonded parts, with the objective to have no strain between electrode and adhesive (mechanical decoupling), which would have distorted the
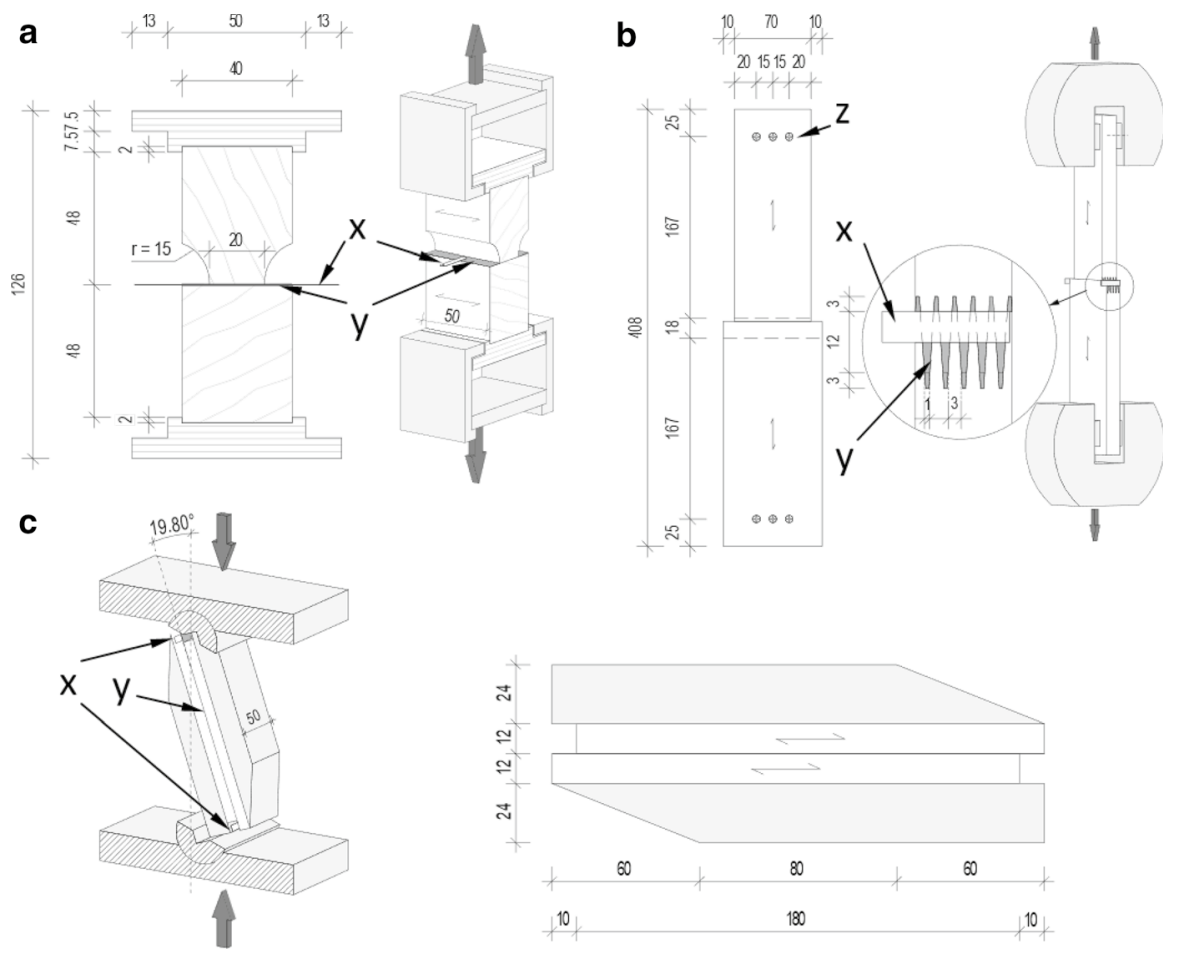

Fig. 2 Design and dimensions of simple specimen for testing the piezoresistive reaction in transversal tension load $\mathbf{a}$, tension load in tapered finger joints $\mathbf{b}$ and compressive shear load $\mathbf{c}$, all with an electrode from Hilumin sheet $(\mathrm{x})$ and electrically conductive adhesive (y) 
PR. Electrical connection was done by sheets made from HILUMIN®, an electrolytically nickel-coated strip steel, usually applied in the battery industry.

In a second iteration, upscaling was realised by the production of two glulam beams with different isolated measurement points (Fig. 3) by partly applying electrically conductive adhesive in certain areas of stress. These measurement points were chosen with the intention of predominant transversal tension stress at a notched beam as well as shear stress, tension stress in tapered finger joints and compression stress in the second beam.

a
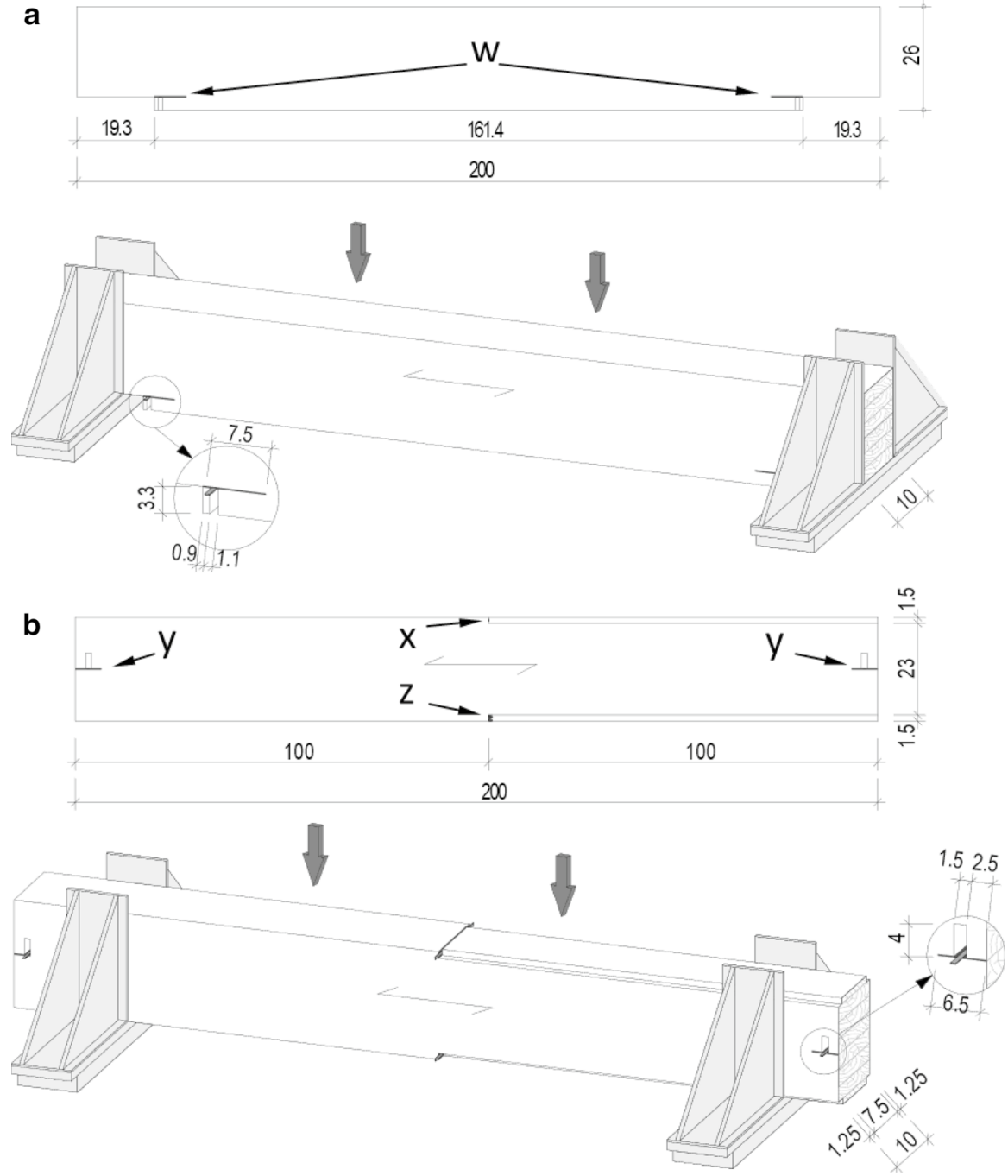

Fig. 3 Design and dimensions of specimen for testing the piezoresistive reaction in glulam beams with electrically conductive adhesive partly applied to measure transversal tension stress (w), compression stress (x), shear stress (y) and tension stress in finger-jointed lamellas (z) 
Thus, the measurements of the first set of samples were upscaled and supplemented by compression stress.

Mechanical decoupling was realised by partly removing material near the electrode by drilling (transversal tension, shear) and offsets between two lamellas (tension in tapered finger joints and compression). Additional photographs with indicated features are available as online supplementary material.

From the design of all specimens, it was found that the resistance is always measured along the adhesive bond line and stresses are applied perpendicular to this direction. Thus, and because three-dimensional experiments especially with orthotropic materials always result in several stress components, the main stress within these test settings (transversal tension, shear, tension and compression) will be used in further references.

\section{Sample preparation}

All specimens were manufactured from spruce wood (Picea abies L.) of strength category C24 (according to EN 338 (EN 338, 2016)), which has been conditioned at a standard climate of $20{ }^{\circ} \mathrm{C}$ and $65 \% \mathrm{RH}(20 / 65)$ until equilibrium moisture content. The different parts of the specimens were cut from the conditioned wood, planed prior to bonding and, for mechanical decoupling, prepared by drilling/cutting out parts near the electrode. Adhesive was prepared by dispersing $4 \mathrm{wt} \%$ carbon black (CB) (Ketjenblack EC-300 J, Akzo Nobel Functional Chemicals B.V., Arnhem, Netherlands) into a one-component polyurethane prepolymer (laboratory prototype 1506-PV, Jowat SE, Detmold, Germany) by using a dissolver (Dispermat CV-SIP, VMA-Getzmann GMBH, Reichshof, Germany). Compared to other electrically conductive nanofillers with strong agglomerates, CB only needs a good homogenisation (Köckritz et al. 2015) and, in case of moisture curing 1C-PUR, other preparations. To prevent moisture uptake during preparation, the $\mathrm{CB}$ was dried to equilibrium at $103.5^{\circ} \mathrm{C}$ and the dispersion process was performed under argon atmosphere. A filler content of $4 \mathrm{wt} \%$ was chosen according to previous investigations and exceeded the percolation threshold, giving a reliable piezoresistivity and reproducibility (Winkler et al. 2020a). $400 \mathrm{~g} / \mathrm{m}^{2}$ of electrically conductive adhesive was spread on the preplanned lamellas using a glass scraper. Electrodes, made from HILUMIN@ strips with a thickness of $0.1 \mathrm{~mm}$, width of $5 \mathrm{~mm}$ and length of $30 \mathrm{~mm}$, were prefixed by a two-component epoxy resin (Bocoll 2-K-Epoxy-Reparaturharz, Boldt \& Co. Vertriebs OHG, Wermelskirchen, Germany) and contacted by the liquid electrically conductive adhesive. All specimens were pressed by clamps according to the result of previous studies. These showed a minor influence of applied pressure between 0.6 and 1.2 $\mathrm{MPa}$ on the tensile shear strength, electrical DC resistance and piezoresistive sensitivity of piezoresistive bond lines in wood (Winkler et al. 2020a; Winkler et al. 2020b).

After $24 \mathrm{~h}$ of curing at room climate $\left(20^{\circ} \mathrm{C} / 35 \% \mathrm{RH}\right)$, the electrodes were mechanically fixed by locally applying a two-component epoxy resin (Bocoll 2-K-Epoxy-Reparaturharz, Boldt \& Co. Vertriebs OHG, Wermelskirchen, Germany). 

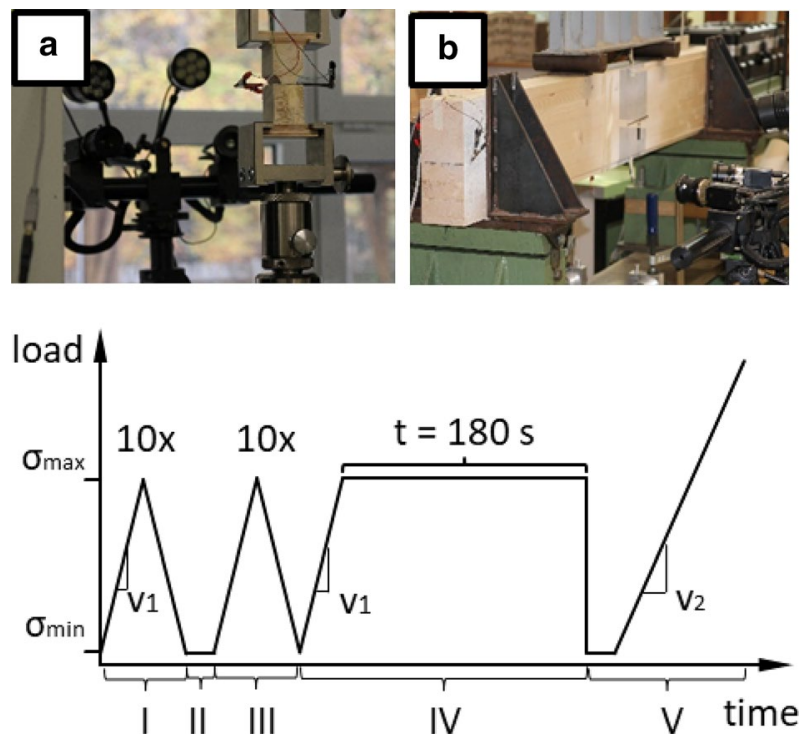

Fig. 4 Pictures from testing the transversal tension specimen (a), glulam beam B from Fig. 3 (b) and test sequence with (I) mechanical condition phase, (II) unloading, (III) piezoresistive response, (IV) constant load and (V) load until break. The glulam beams were only tested according to phase IV, but repeating in the elastic range

Table 1 Test parameters for all mechanical tests according to Fig. 4 of specimen defined in Figs. 2, 3

\begin{tabular}{llllll}
\hline Specimen (number) & $\begin{array}{l}\sigma_{\min } \\
{[\mathrm{MPa}]}\end{array}$ & $\begin{array}{l}\sigma_{\max } \\
{[\mathrm{MPa}]}\end{array}$ & $\mathrm{V}_{1}$ & $\begin{array}{l}\mathrm{V}_{2} \\
{[\mathrm{MPa} / \mathrm{s}]}\end{array}$ & Test phases \\
\hline Transversal tension $(n=30)$ & 0.1 & 0.6 & $0.2 \mathrm{MPa} / \mathrm{s}$ & 0.05 & $\mathrm{I}-\mathrm{V}$ \\
Tension $(n=18)$ & 0.1 & 10.0 & $1.5 \mathrm{MPa} / \mathrm{s}$ & 0.2 & $\mathrm{I}-\mathrm{V}$ \\
Push-shear $(n=12)$ & 0.15 & 3.15 & $0.2 \mathrm{MPa} / \mathrm{s}$ & 0.05 & $\mathrm{I}-\mathrm{V}$ \\
Glulam beam A $(n=1)$ & $0 \mathrm{kN}$ & $40 \mathrm{kN}$ & $250 \mathrm{~N} / \mathrm{s}$ & - & $\mathrm{IV} *$ \\
Glulam beam B $(n=1)$ & $0 \mathrm{kN}$ & $40 \mathrm{kN}$ & $250 \mathrm{~N} / \mathrm{s}$ & - & $\mathrm{IV}^{*}$ \\
\hline
\end{tabular}

The finger-jointed specimens were reinforced against transverse compression by adding three fully threaded screws (diameter $4 \mathrm{~mm}$ ).

\section{Measuring setup}

All specimens were tested according to the sequences pictured in Fig. 4. The parameters of the test sequences together with the number of specimens in each test are given in Table 1. Phase I and III are load-wise the same, but only phase III is used to characterise the piezoresistive reaction in this manuscript (see "Piezoresistive reaction"section ). Phase I was introduced in the test sequence to mechanically condition the sample. Phase II ( $\sigma_{\min }$ for $20 \mathrm{~s}$ ) was added to distinguish between phase I 
and III and shows the stability of the baseline resistance. Phase IV is used to evaluate the mechanical and electrical creep under constant load. Phase V is used to analyse the behaviour until break. The beams were tested only according to phase IV. The maximum stresses in the first set of samples were derived from the strength category C24 (according to EN 338 (EN 338, 2016)) under the assumption that timber fails before the adhesive bond line.

For testing of the first set of samples, a universal testing machine (Zwick/Roell Type 1484, load cell $200 \mathrm{kN}$, Ulm, Germany) was used. The beams were loaded in a testing rack at the Eberswalde University of Applied Sciences (WPM 600 kN, WPM Leipzig, Leipzig, Germany; load cell 500 kN, A.S.T.-Angewandte Systemtechnik GmbH, Dresden, Germany).

Measurements of electrical resistance under direct current $\left(\mathrm{R}_{\mathrm{DC}}\right.$ measurements) were performed by a two-wire method for the first set of samples (NI PXI-4071, National Instruments $\mathrm{GmbH}$, Munich, Germany) and a four-wire method for the beams, which were multiplexed to all measurement points in each beam (NI PXI4071 and NI PXI-2527, National Instruments GmbH, Munich, Germany). Connection of the resistometer and the electrodes was realised by shielded cables and spring-loaded contacts. The measurement and analysis of the strain near the adhesive bond line were performed by digital image correlation (DIC) with two cameras (Aramis 3D, 5 M cameras, GOM GmbH, Braunschweig, Germany).

The presented data were partly smoothed (moving average, 10 points) for better understanding. In all cases, the smoothed data are specified in the legends of the graphs. The piezoresistive sensitivity - the fractional change of resistance per stress-was calculated from the smoothed data. The data from mechanical testing (load/force/traverse path/strain) were synchronised, using the timestamp of both measuring computers. Thus, the mismatch amounted to a maximum of $1 \mathrm{~s}$ and these timestamps were marked as synchronised time or-for clearer figures-time in the figure.

\section{Results and discussion}

\section{Piezoresistive reaction}

Phase III (Fig. 4) was analysed for the piezoresistivity, and the results are given in Table 2 together with the baseline resistance $R_{B L}$. The baseline resistance differs with type of specimen, reaching a range of around 2 to $50 \mathrm{kOhm}$. It has been shown in earlier work that the baseline resistance does not affect the sensitivity of piezoresistive bond lines in wood (Winkler et al. 2020b) after exceeding the percolation range (Winkler et al. 2020a).

The piezoresistive sensitivity under direct current $S_{D C}$ in Table 2 represents the relative change of electrical resistance per unit stress (calculated from load divided by the cross section) or, in the case of unknown stresses in the glulam beams, the relative change of electrical resistance in respect of the maximum load, which was defined in Fig. 4. The PR shows whether the resistance under direct current is increasing $(+)$ or decreasing $(-)$ with increasing stress. In case 
Table 2 Results from the different load situations in simple specimens and glulam beams with baseline resistance $\left(\mathrm{R}_{\mathrm{BL}}\right)$, piezoresistive sensitivity under direct current $\left(\mathrm{S}_{\mathrm{DC}}\right)$ and the sign for the measured piezoresistivity (PR)

\begin{tabular}{lllll}
\hline Specimen & $\mathrm{R}_{\mathrm{BL}}(\mathrm{k} \Omega)$ & $\mathrm{S}_{\mathrm{DC}}[\% / \mathrm{MPa}]$ & $\mathrm{S}_{\mathrm{DC}}\left[\% / \sigma_{\max }\right]$ & $\mathrm{PR}[\operatorname{sign}]$ \\
\hline Transversal tension $\sigma_{\mathrm{t},},(n=30)$ & $33.7 \pm 15.6$ & 0.14 & 0.084 & $-(28 / 30) ;+(1 / 30)$ \\
Tension in finger joints $\sigma_{\mathrm{t}}(n=18)$ & $2.7 \pm 0.3$ & 0.25 & 2.5 & + \\
Push-shear $\tau_{\mathrm{c}}(n=9)$ & $17.8 \pm 3.1$ & 0.805 & 2.536 & $+(9 / 12) ;-(2 / 12)$ \\
Transversal tension $\sigma_{\mathrm{t}, \mathrm{t}}$ glulam $(n=2)$ & $4.7 / 4.7$ & - & $0.15 ; 0.12$ & + \\
Bending-tension $\sigma_{\mathrm{m}(\mathrm{t})}$ glulam $(n=1)$ & 2.2 & - & 0.20 & + \\
Push-shear $\tau_{\mathrm{c}}$ glulam $(n=2)$ & $17.8 / 23.8$ & - & $0.07 ; 0.06$ & + \\
Bending-compression $\sigma_{\mathrm{m}(\mathrm{c})}$ glulam & 7.2 & - & 0.39 & - \\
$\quad(n=1)$ & & & & \\
\hline
\end{tabular}

of a difference in PR in the set of samples, the ratio in brackets represents the rate of samples for the given sign $(+/-)$.

A visual overview of the PR of the first set of specimens is given in Fig. 5 with an example for each specimen. For specimens with different PR, the majority is represented.

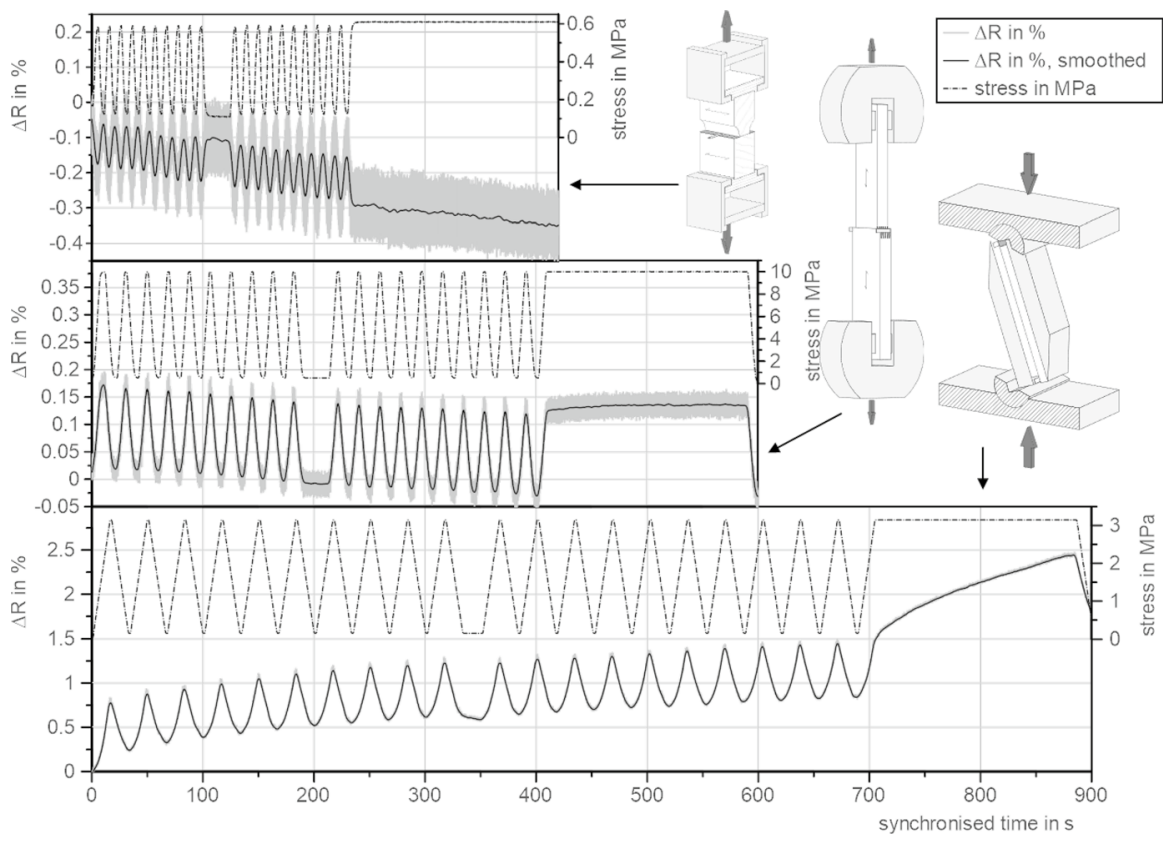

Fig. 5 Example data from the first set of specimens, showing the piezoresistive reaction to the different stresses. The results from the tested glulam beams are visualised in Fig. 6 with all measured points in relation to the applied force in the test rack 
From the set of 30 transversal tension tests, 28 specimens showed a negative PR, one a positive PR and one specimen did not show a visible reaction at all. The set of tension tests showed a consistent positive PR in all 18 samples. The set of 12 pushshear-tests showed 11 times a PR, nine times positive and two times negative.

The tests of the glulam beams (Fig. 6) result in positive PRs for all measuring points, except the bond line with compression stress. The doubled-up measurement points (transversal tension stress and shear stress) in the glulam beams show a comparable PR, but all monitored points give a different extent of PR, starting with compression load as the highest, followed by tension in tapered finger joints, transversal tension and shear with the lowest fractional change during the whole experiment of $0.06 \%$.

Contrary to the lowest $\mathrm{S}_{\mathrm{DC}}$ for shear in the glulam beam, the push-shear-tests in the first set of samples showed the highest $\mathrm{S}_{\mathrm{DC}}$ compared to the other specimen, followed by the specimen in tension and transversal tension with the lowest $\mathrm{S}_{\mathrm{DC}}$.

Finally, it is visible that all samples in the first test setup show a drift in the resistance signal, which is negative for transversal tension and positive for shear with compression. For the specimen in tension, the drift is changing from negative (phase I to III) to positive (phase IV).

Even though PR could be measured in all load situations (and therefore, the hypothesis was proven positive), the following questions arose from the data set:

1. Why did some samples not show a measurable PR?

2. Why is the extent of PR different for different load situations?

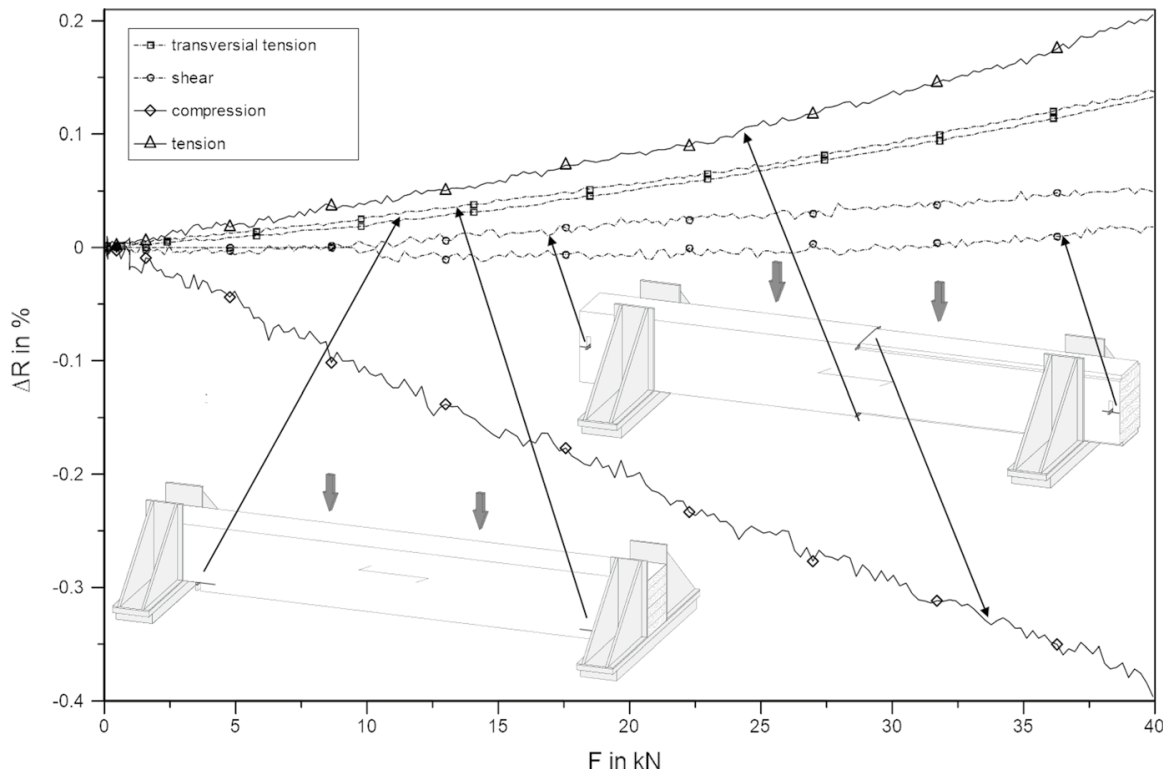

Fig. 6 Relative change in electrical resistance as a function of test load at all measured points of the glulam beams (the marker represents every twentieth point) 
3. Why is the PR in transversal tension of the first set of samples mainly positive, but negative in glulam beam testing?

4. Why did the specimens in transversal tension load and shear with compression load show inverse PR in some samples?

5. Why do most samples show a drift in electrical resistance during the measurement?

The first question is explainable by the extent of noise during the measurement. All samples with no PR show a noise of the resistance in the order of around $25 \%$, which is several magnitudes higher than the average $\mathrm{S}_{\mathrm{DC}}$ of $0.15 \% / \mathrm{MPa}$.

For all other questions, it is first necessary to look upon the theoretical threedimensional stress distribution in each specimen and consider how strain and electrical resistance measurement direction are located.

\section{Strain analysis}

Piezoresistivity and PR are influenced by the macroscopic strain $(\Delta \mathrm{l} / \mathrm{l})$ in resistance measurement direction as well as the specific resistance of the material, which is changed by microstrains $(\Delta \rho / \rho)$ (see also Eq. 1$)$.

In general, under the assumption of co-linear strain and electrical resistance measurement, the electrical resistance in

- specimens under tension increases due to the increasing conductor length $(+\Delta \mathrm{l} / \mathrm{l})$ and distance between conducting particles, which decreases the amount of conducting paths in the material $(+\Delta \rho / \rho)$

- specimens under compression decreases due to the decreasing conductor length $(-\Delta \mathrm{l} / \mathrm{l})$ and distance between conducting particles, which increases the amount of conducting paths in the material $(-\Delta \rho / \rho)$

Figure 7 gives a proposed model of the macroscopic and microscopic influences on the PR.

The upper part shows the theoretical stresses in the tested load situation of the first set of samples with transversal tension (a), tension in finger joints (b) and shear with compression (c) as well as the glulam beam tests with transversal tension (a'), tension in finger joints (b), shear (c') and compression (d). For a clearer diagram, the minor stresses perpendicular to the depicted area are not shown. The shown strain is the strain in direction of the resistance measurement, with compression strain negative and tension strain positive. The lower part pictures the microstructural changes, focusing on the change in specific resistance with microstrain. All strains and specific resistance changes in brackets are meant to be restricted by the structure of glulam beams. As the lamellas are bonded in layers, the transverse deformation is more restricted than in the specimen of the first set.

In addition, crucial for the understanding is the alignment of electrical resistance measurement direction with the micro shear in the bond line. On one side, if the shear is aligned with the measurement of resistance, the PR will be positive as 


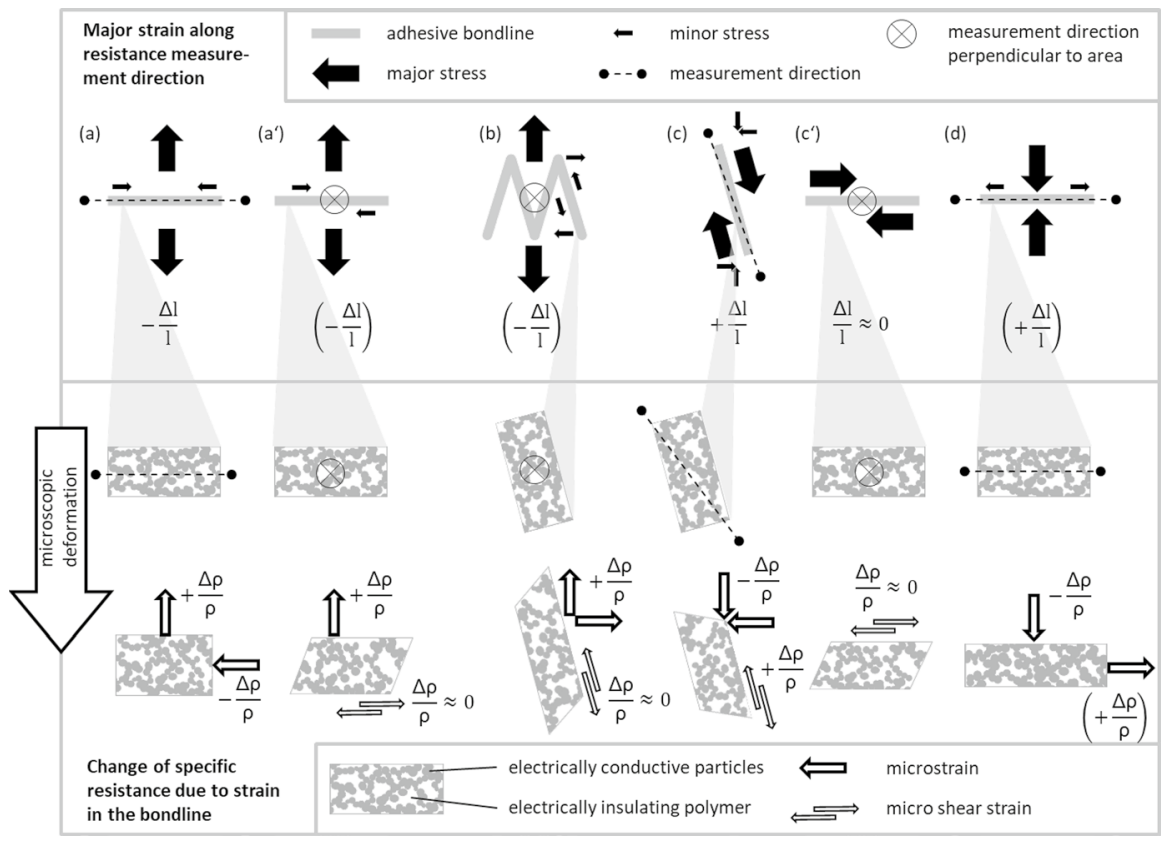

Fig. 7 Model of strains, which influence the piezoresistive reaction of the electrically conductive bond line in wood with the tested load situations a transversal tension (a') transversal tension in glulam beam b tension in finger joints $\mathbf{c}$ compression shear (c') shear in glulam beam and (d) compression in glulam beam, with strain $(\Delta \mathrm{l} / \mathrm{l})$ and change in specific resistance $(\Delta \rho / \rho)$

inter-particle distance will increase, similar to tension. On the other side, shear will not or less influence the specific resistance if the measurement direction is perpendicular to the shear field. In this case, the inter-particle distance has a lower ranked influence.

First of all, it is evident from the differentiation of $(\Delta \mathrm{l} / \mathrm{l})$ and $(\Delta \rho / \rho)$ that the macroscopic strain cannot be the only influence on the PR, as only for the specimen in compression shear mode do the strain and PR correlate. Thus, the microstrain has an influence.

Despite the fact that the real three-dimensional strain measurement of the microstrain in the bond line is beyond the scope of this work, the model of microstrains can answer the second question and explain the differences between the extent of PR in the measurements.

As there are opposed strains in each setup, the extent of PR can be decreased by opposing strains. For example, the specimen under shear with compression (Fig. 7c) would have a positive PR from the macroscopic strain (elongation of the conductor) as well as from the microscopic strain (increasing distance between particles). The experimental results show one of the highest extents of PR for this specimen.

In addition, the strains in the shear region of the glulam beam (Fig. 7c') are proposing no or at least only small amounts of $S_{D C} / P R$ and the experimental results show the lowest extent of $S_{D C}$ (Table 2), partly with a negative PR (Fig. 6). 
To explain the differences of PR (second question), the strain distribution was analysed by DIC as described before (see "Measuring setup") on the surface of the transversal tension specimen in the first set as well as transversal tension in the glulam beams. With the DIC method, it was possible to measure the strain near the bond line and therefore estimate the Poisson's ratio of the strained bond line. The different strains are visualised in Fig. 8, together with the locations of the measurement.

Mainly, the strain distribution near the bond line fitted the proposed strain model in Fig. 7.

In Fig. 8a, the measurement points for strain near the bond line of the specimen under transversal tension are shown. Figure $8 a^{\prime}$ visualises the strain in the elastic regime of a sample with positive PR, and Fig. 8a' shows a sample with negative PR. Both specimens show a typical behaviour with higher strain in transversal tension (y-axis) than in lateral contraction (x-axis), thus giving no indication of the influence. On the other side, a difference is visible by the calculated Poisson's ratio. While the specimen with positive PR gives a Poisson's ratio $v$ of $0.65 \pm 0.05$, the specimen with negative PR gives a $v$ of $0.82 \pm 0.01$. These Poisson's ratios arecontrary to the limits of -1 to 0.5 for isotropic materials (Ting and Chen 2005) possible and in accordance with theoretical (Mentrasti et al. 2021) and experimental literature (Kumpenza et al. 2018) on orthotropic materials like wood. This leads to the conclusion that the compression in direction of the x-axis, which is identical with the direction of the resistance measurement, is relatively higher compared to the tension perpendicular to the measurement direction. As compression-induced
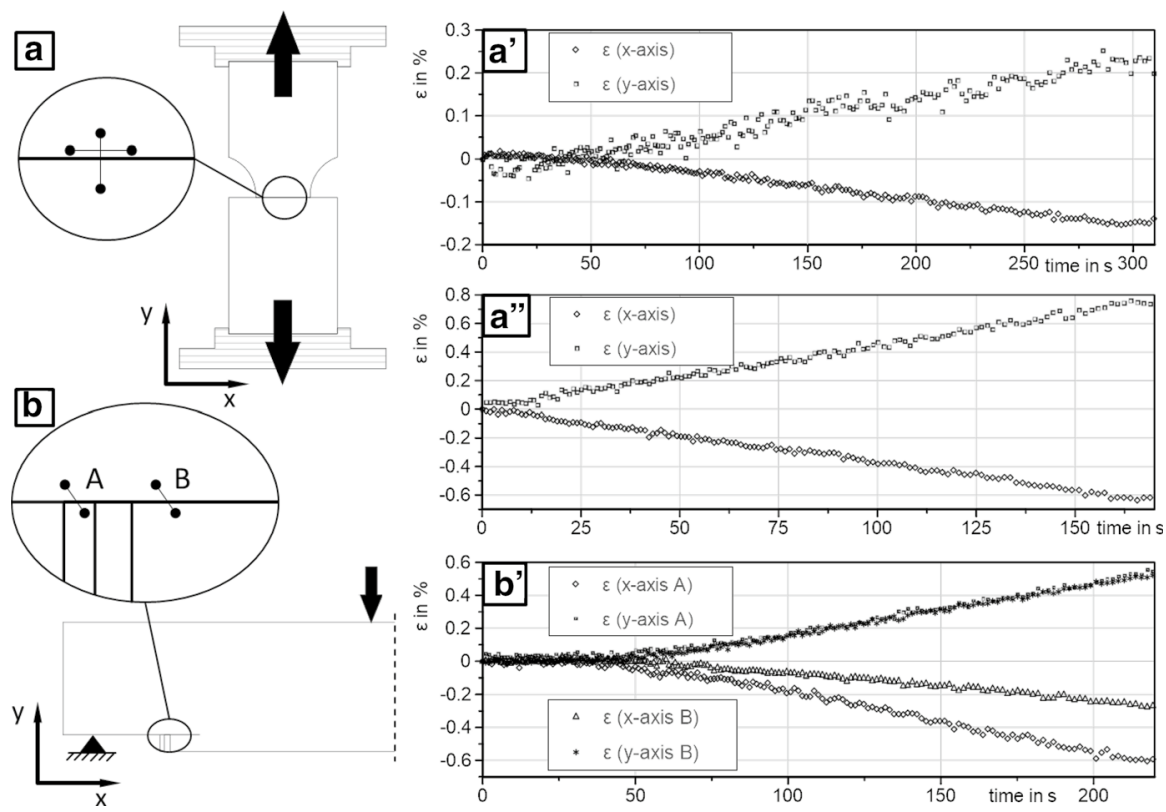

Fig. 8 DIC measuring location at specimen from the first set $\mathbf{a}$ as well as the notched glulam beam $\mathbf{b}$ together with the calculated strain (right) of one positive (a') and one negative (a') piezoresistive transversal tension specimen and the strain at the glulam notch (b') 
PR is theoretically negative, the negative piezoresistivity in the specimen can be explained by a higher influence of compression strain. This leads to the conclusion that.

1. the majority of the tested samples of the first set exhibits higher lateral contraction compared to the transversal tension.

2. even if there are multiple stress situations while testing this specimen, the results are consistent and it is possible to detect the dominant strain with the piezoresistive bond line.

Figure $8 b^{\prime}$ also shows that transversal tension strain is not dominant in the notched glulam beam as the highest shear strain is on the same level of around $0.6 \%$. As shear in this specimen design is supposed to not influence the PR (see Fig. 7a'), the positive PR has its origin in the transversal tension microstrain of the bond line.

\section{Inverse piezoresistive reaction}

Three samples in all tests showed an inverse PR, from which the one from the transversal tension set was discussed and explained by strain analysis. In Fig. 9, the two samples with inverse PR of the shear with compression are shown.

Now, as the strain analysis showed that overlapping stress states can be contractionary to the PR, the resistance reaction of the two inverse samples is comprehensible. From the theory of the specimen design, a minor influence of compression stress, therefore negative PR, is possible, while the main influence-shear stressshould exhibit positive PR (see also Fig. 7).

In both specimens shown in Fig. 9, a change in PR is visible. In sample (a), the resistance increases first (positive PR) but after a certain load, the PR becomes negative (Fig. 9a'). Sample (b) starts with decreasing resistance (negative PR), but changes to an increasing resistance with higher loads (positive PR), shown in Fig. 9 b'. As the PR of both samples is repeatable, an influence of damage accumulation (Myslicki et al. 2017) can be excluded as the cause of the erratic behaviour. It must be concluded that the change in piezoresistivity origins presumably from the change in the predominant strain or microstrain.

From the data set it cannot be identified why these two samples show a higher compression strain after a certain load. On the other side, it is known from wood that annual ring angle has a high influence on the stress transfer as well as the Poisson's ratio, ranging from 0.014 to 0.739 for spruce (Kumpenza et al. 2018; Niemz and Sonderegger 2017). Thus, a relatively higher influence of compressive strain at some load periods is a reasonable explanation.

\section{Resistance drift}

In all measurements of the first set of samples, a drift in electrical resistance (RD) during the whole measurement (phase I to VI) was detectable, partly with an asymptotic trend (Fig. 10a and b). In contrast, the resistance measurements at the glulam 


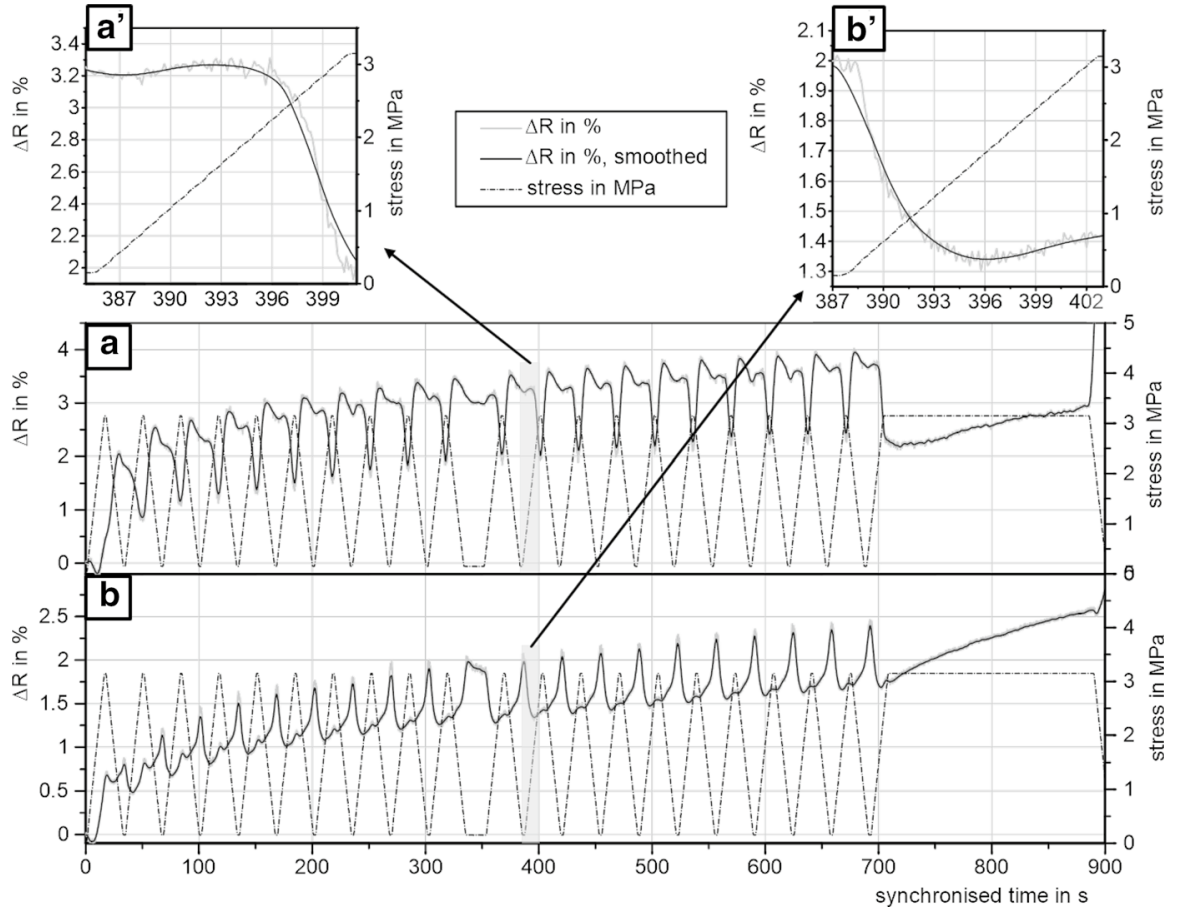

Fig. 9 Inverse piezoresistive reaction in two samples under compression shear load (a and b) and details (a' and b')

beams did not show this RD (Fig. 10c). RD in electrically conductive polymers has also previously been reported in other studies (Abu-Abdeen et al. 2016; Kang et al. 2006; Wang and Ding 2010; Winkler et al. 2020b; Zhao et al. 2013). Possible influences along the measuring chain are the instruments, the measuring method, measuring voltage and current, the measuring cables, the contact resistances and the viscoelastic properties of the sensor (the adhesive bond line) and the stress transferring material (wood).

As all measurements on the glulam beams showed no drift, the instrument as well as the cables can be excluded as major influences as they would influence all measurements.

A reasonable explanation of the overall negative RD in the first set of sampleseven in the unloaded specimens prior to the measurement (Fig. 10a and b) - is the two-probe method in the first set, which includes the contact resistance (Chung 2010). Together with the measurement method, the source voltage and current can also alter the RD, which has been investigated for voltage by Paredes-Madrid on electrically conductive filled polymers, leading to positive or negative RD (ParedesMadrid et al. 2017). Depending on the baseline resistance (Table 2), the test current of the used instrument was $100 \mu \mathrm{A}$ (for $\mathrm{R}_{\mathrm{BL}} \leq 10 \mathrm{kOhm}$ ) and $10 \mu \mathrm{A}$ (for $\mathrm{R}_{\mathrm{BL}} \leq 100$ $\mathrm{kOhm})$. Thus, an influence from current induced heating at the contact point is unlikely, but not fully excludable. 

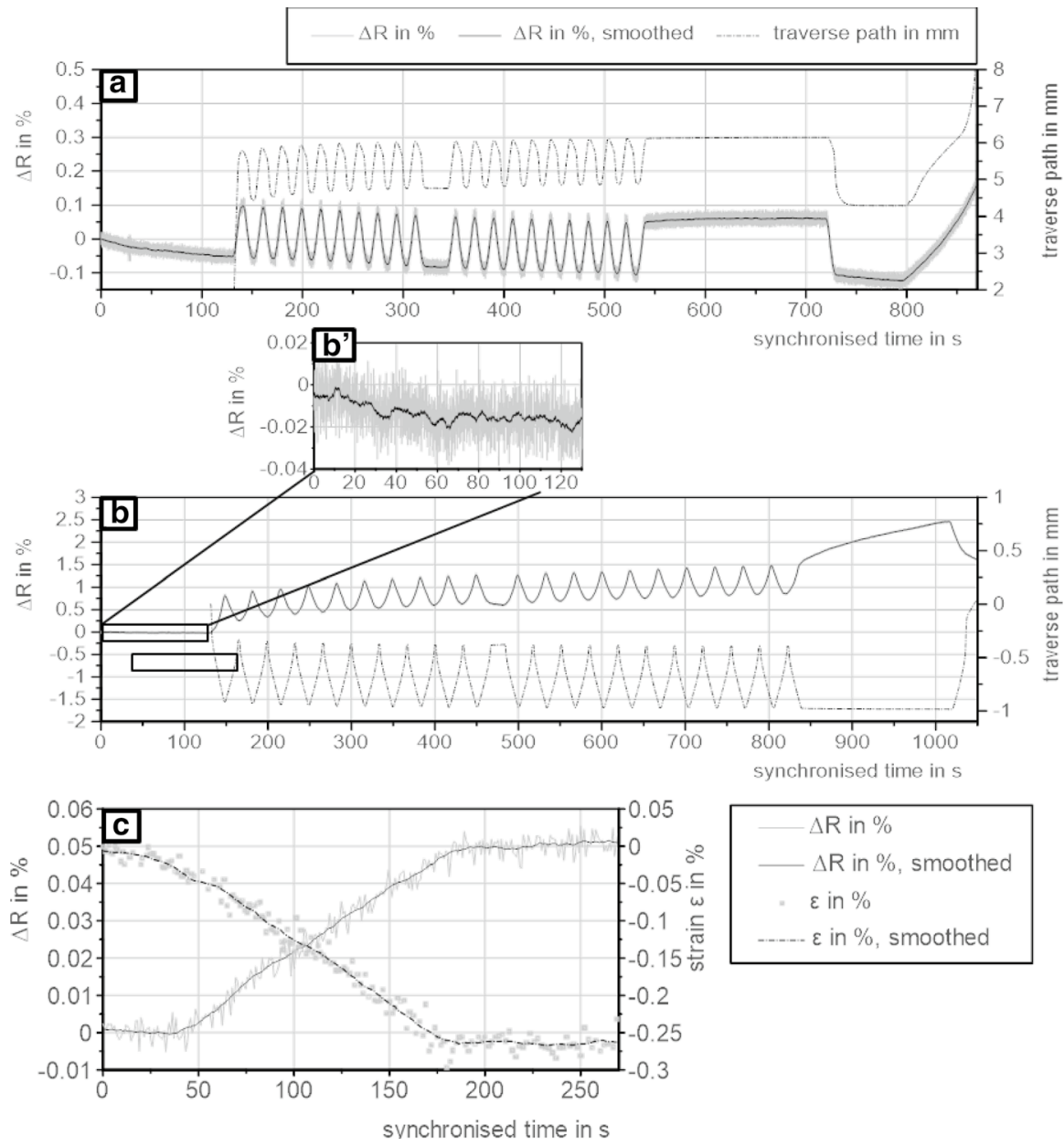

Fig. 10 Examples of electrical resistance drift and traverse path during load-controlled testing for a tension in finger-jointed specimen, $\mathbf{b}$ compression shear stress and $\mathbf{c}$ electrical resistance change in one shear loaded measuring point in glulam beam $b$, together with the DIC measured strain

On the other hand, an additional positive drift of electrical resistance becomes visible, when the specimens are loaded. As the drift shows an asymptotic behaviour similar to creep in viscoelastic material, creep of the stress transferring wood adherend as well as the polymer of the multifunctional adhesive are possible influences. The deformation of the whole specimen was measured by the traverse path of the testing machine, but reveals only a small drift at the beginning of the test, which did not correlate with the positive drift of electrical resistance, for example in compression shear stress (Fig. 10a).

At least there are two remaining influences from measuring setup and the material, which need to be analysed with an adjusted test setup to isolate the influences and find a conclusion. 


\section{Load until failure}

The first set of specimens was partly tested until failure, which gives insight into the PR at higher stress levels and until failure. The results of load until failure are shown in Fig. 11. Figure 11a visualises the PR until failure of a specimen under shear with compression. Additionally, it represents the PR until failure of the majority of samples with positive PR. The nonlinearity presented in Fig. 11a is more distinct for specimens with higher electrical drift like the specimen under shear load. Piezoresistive measurements in the glulam beam specimen showed a linear response (see Fig. 6).

A behaviour shared by all specimens under test is a positive PR before failure, which can especially be seen in Fig. $6 \mathrm{~b}$ and Fig. 6c, representing negative piezoresistive samples in transversal tension and shear load. The change in PR always occurs

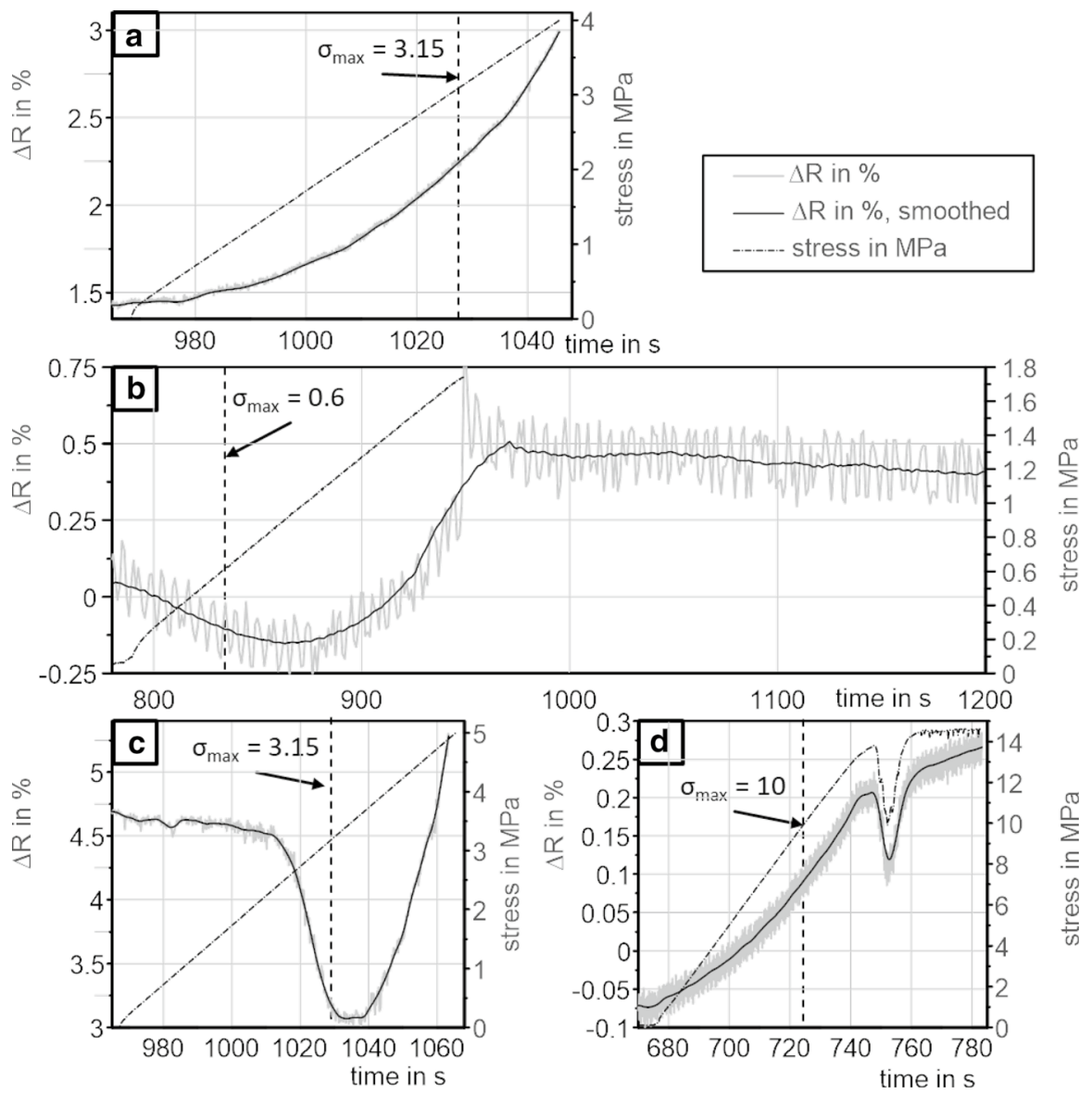

Fig. 11 Piezoresistive reaction until failure from the first set of samples with a and $\mathbf{c}$ under compressive shear load, b under transversal tension load and $\mathbf{d}$ under tension load in finger joints 
after the maximum load $\sigma_{\max }$ during Phase I to IV, indicating that either the maximum strength of the material is reached, resulting in a plastic deformation or the tension/shear-based stresses became predominant in the sample. Figure 11d gives at least an example of pre-cracking (clearly audible) before failure in the finger-jointed specimen under tensile load.

\section{Conclusion}

The experimental results from using electrically conductive adhesives in engineered timber were presented and discussed, focussing on the upscaling of earlier studies. The necessity of specimen design regarding the electrical contact and different specimen design for measurements of transversal tension, tension in finger joints, compression and shear are presented. All results clearly show the PR of the multifunctional adhesive bond line could be used to detect stresses. Further questions are discussed in the paper, including inverse PRs, signal drifting and behaviour until failure, coming up by evaluation of the tests.

A model to explain the results from the point of view of piezoresistive properties was designed. Further investigation is needed to include the restrictions of the threedimensional strain analysis inside bond line and materials. The following conclusions can be drawn from the results:

1. It is possible to detect strains and the related stresses in glulam beams by means of the piezoresistive properties of the electrically conductive bond lines.

2. The PR turns positive prior to overloading and failure, even if the resistance was decreasing in the elastic regime.

3. In several measurements, a drift in electrical resistance could be measured but not traced back to one cause. Thus, the cause of the electrical drift needs to be investigated in detail.

Under the assumption of the model concept:

4. Electrically conductive adhesive bond lines in wood exhibit piezoresistive behaviour in accordance with the theory, showing negative PRs in compression and positive in tension.

5. In shear, the direction of measurement is crucial, decreasing the sensitivity if the electrical resistance is measured perpendicular to the shear field.

6. The results suggest that the piezoresistive adhesive bond line will measure the dominant stress state at the measurement point, thus overlapping stress states could lead to an increase or decrease in PR.

Supplementary Information The online version contains supplementary material available at https://doi. org/10.1007/s00226-021-01305-6. 
Funding Open Access funding enabled and organized by Projekt DEAL. This work was supported by the German Government within the „Nachwachsende Rohstoffe “ program (FNR, BMEL) under Grant 22005018.

Availability of data and material Available upon request: christoph.winkler@hnee.de.

\section{Declarations}

Conflict of interest On behalf of all authors, the corresponding author states that there is no conflict of interest.

Open Access This article is licensed under a Creative Commons Attribution 4.0 International License, which permits use, sharing, adaptation, distribution and reproduction in any medium or format, as long as you give appropriate credit to the original author(s) and the source, provide a link to the Creative Commons licence, and indicate if changes were made. The images or other third party material in this article are included in the article's Creative Commons licence, unless indicated otherwise in a credit line to the material. If material is not included in the article's Creative Commons licence and your intended use is not permitted by statutory regulation or exceeds the permitted use, you will need to obtain permission directly from the copyright holder. To view a copy of this licence, visit http://creativecommons.org/licen ses/by/4.0/.

\section{References}

Abu-Abdeen M, Aboud AI, Ramzy GH (2016) Effect of Temperature on creep behavior of poly(vinyl chloride) loaded with single walled carbon nanotubes. Int J Sci Eng App 5:112-120. https://doi.org/ 10.7753/IJSEA0503.1001

Balageas D, Fritzen C-P, Güemes A (eds) (2006) Structural Health Monitoring. Iste Publishing Company, London

Kasal B, Tannert T (eds) (2010) In Situ Assessment of Structural Timber. State of the Art Report of the RILEM. Springer, Heidelberg

Chung DDL (2010) Functional Materials: Electrical, dielectric, electromagnetic, optical and magnetic applications. Engineering materials for technological needs, vol 2. World Scientific, Singapore

Chung DDL (2020) A critical review of piezoresistivity and its application in electrical-resistance-based strain sensing. J Mater Sci 55:15367-15396. https://doi.org/10.1007/S10853-020-05099-Z

EN 338 (2016) Structural timber - Strength classes. European Committee for Standardization (CEN), Brussels

Filon LNG (1903) On an approximate solution for the bending of a beam of rectangular cross-section under any system of load, with special reference to points of concentrated or discontinuous loading. Phil Trans r Soc Lond A 201:63-155. https://doi.org/10.1098/rsta.1903.0014

Franke S, Franke B, Rautenstrauch K (2007) Strain analysis of wood components by close range photogrammetry. Mater Struct 40:37-46. https://doi.org/10.1617/s11527-006-9152-6

Han S, Meng Q, Araby S, Liu T, Demiral M (2019) Mechanical and electrical properties of graphene and carbon nanotube reinforced epoxy adhesives: Experimental and numerical analysis. Compos Part A-Appl S 120:116-126. https://doi.org/10.1016/j.compositesa.2019.02.027

Jahreis MG, Rautenstrauch K (2016) High-Efficient Joint System for Timber Engineering with Casted-in Connectors. In: Eberhardsteiner J, Winter W, Fadai A (eds) World Conference on Timber Engineering (WCTE 2016): Vienna, Austria, 22-25 August 2016. Vienna University of Technology, Vienna

Kang I, Schulz MJ, Kim JH, Shanov V, Shi D (2006) A carbon nanotube strain sensor for structural health monitoring. Smart Mater Struct 15:737-748. https://doi.org/10.1088/0964-1726/15/3/009

Kästner M, Jahreis MG, Hädicke W, Rautenstrauch K (2014) Development of Continuous Composite Joints on the Basis of Polymer Mortar with matched Properties. In: Salenikovich A (ed) World Conference on Timber Engineering (WCTE 2014): Quebec City, Canada, 10-14 August 2014. Curran Associates Inc, Red Hook, NY 
Koch J, Simon A, Arndt RW (2016) Monitoring of moisture content of protected timber bridges. In: Eberhardsteiner J, Winter W, Fadai A (eds) World Conference on Timber Engineering (WCTE 2016): Vienna, Austria, 22-25 August 2016. Vienna University of Technology, Vienna

Köckritz T, Wehnert F, Pap J-S, Jansen I (2015) Increasing the Electrical Values of Polydimethylsiloxane by the Integration of Carbon Black and Carbon Nanotubes: a Comparison of the Effect of Different Nanoscale Fillers. J Adhes Soc Jpn 51:221-222. https://doi.org/10.11618/adhesion.51.221

Kumpenza C, Matz P, Halbauer P, Grabner M, Steiner G, Feist F, Müller U (2018) Measuring Poisson's ratio: mechanical characterization of spruce wood by means of non-contact optical gauging techniques. Wood Sci Technol 52:1451-1471. https://doi.org/10.1007/s00226-018-1045-7

Kurz JH (2015) Monitoring of timber structures. J Civil Struct Health Monit 5:97. https://doi.org/10. 1007/s13349-014-0075-6

Kurz JH, Boller C (2015) Some background of monitoring and NDT also useful for timber structures. J Civil Struct Health Monit 5:99-106. https://doi.org/10.1007/s13349-015-0105-z

Mang HA, Hofstetter G (2013) Mechanics of Materials (Festigkeitslehre), 4th edn. Springer Vieweg, Berlin, Heidelberg

Masaebi N, Peighambardoust SJ, Ahadzadeh I (2018) Electrically conductive nanocomposite adhesives based on epoxy resin filled with silver coated nanocarbon black. J Mater Sci Mater Electron 29:11840-11851. https://doi.org/10.1007/s10854-018-9284-9

Massoumi B, Hosseinzadeh M, Jaymand M (2015) Electrically conductive nanocomposite adhesives based on epoxy or chloroprene containing polyaniline, and carbon nanotubes. J Mater Sci Mater Electron 26:6057-6067. https://doi.org/10.1007/s10854-015-3183-0

Mentrasti L, Molari L, Fabiani M (2021) Poisson's ratio bounds in orthotropic materials. Application to natural composites: wood, bamboo and Arundo donax. Compos Part B-Eng 209:108612. https://doi. org/10.1016/j.compositesb.2021.108612

Myslicki S, Winkler C, Gelinski N, Schwarz U, Walther F (2017) Fatigue assessment of adhesive wood joints through physical measuring technologies. In: Fatigue 2017: 7th International Conference on Durability and Fatigue, pp 446-455

Niemz P, Sonderegger WU (2017) Wood Physics (Holzphysik - Physik des Holzes und der Holzwerkstoffe). Fachbuchverlag Leipzig (Carl Hanser), Munich

Oppel M, Jahreis MG, Rautenstrauch K (2016) Numerical constitutive model for wood with specified density function. In: Eberhardsteiner J, Winter W, Fadai A (eds) World Conference on Timber Engineering (WCTE 2016): Vienna, Austria, 22-25 August 2016. Vienna University of Technology, Vienna, pp 2424-2434

Paredes-Madrid L, Matute A, Bareño JO, Parra Vargas CA, Gutierrez Velásquez EI (2017) Underlying Physics of Conductive Polymer Composites and Force Sensing Resistors (FSRs). A Study on Creep Response and Dynamic Loading. Materials (Basel) 10. https://doi.org/10.3390/ma10111334

Santamaria A, Muñoz ME, Fernández M, Landa M (2013) Electrically conductive adhesives with a focus on adhesives that contain carbon nanotubes. J Appl Polym Sci 129:1643-1652. https://doi.org/10. 1002/app.39137

Tannert T, Müller A (2010) Structural health monitoring of timber bridges. In: Malo KA, Kleppe O, Dyken T (eds) In: Proceedings international conference timber bridges (ICTB2010), pp 205-212

Ting TCT, Chen T (2005) Poisson's ratio for anisotropic elastic materials can have no bounds. Q J1 Mech Appl Math 58:73-82. https://urldefense.proofpoint.com/v2/url?u=https-3A__doi.org_10.1093_ qjmamj_hbh021\&d=DwIFaQ\&c=vh6FgFnduejNhPPD0f1_yRaSfZy8CWbWnIf4XJhSqx8\&r= 7GjDei_PxQva2JNOfHbJQKIolTpKkGdW_4o9-CecCzX9fDPu7SrgsodpYCPByYz\&m=Yis1G 9yQzW2uLeNznmgMPv61ZefCIMDYHHMFE5PNccU\&s=WT2HENNuFS8G4kNM8ZpJ0nEV1 gDQ8cmuxicKqGK9Gr8\&e=

Wang P, Ding T (2010) Creep of electrical resistance under uniaxial pressures for carbon black-silicone rubber composite. J Mater Sci 45:3595-3601. https://doi.org/10.1007/s10853-010-4405-8

Wehnert F, Langer M, Kaspar J, Jansen I (2014) Design of multifunctional adhesives by the use of carbon nanoparticles. J Adhesion Sci Technol 29:1849-1859. https://doi.org/10.1080/01694243.2015. 1014536

Winkler C, Schwarz U (2016) Characterization of adhesively bonded wood structures by electrical modification of the bonding system. In: Eberhardsteiner J, Winter W, Fadai A (eds) World Conference on Timber Engineering (WCTE 2016): Vienna, Austria, 22-25 August 2016. Vienna University of Technology, Vienna

Winkler C, Schäfer J, Jager C, Konnerth J, Schwarz U (2020) Influence of polymer/filler composition and processing on the properties of multifunctional adhesive wood bonds from polyurethane 
prepolymers II: electrical sensitivity in compression. J Adhesion 96:185-206. https://doi.org/10. 1080/00218464.2019.1652602

Winkler C, Schäfer J, Jager C, Konnerth J, Schwarz U (2020b) Influence of polymer/filler composition and processing on the properties of multifunctional adhesive wood bonds from polyurethane prepolymers II:electrical sensitivity in compression. J Adhesion 96:185-206.https://urldefense.proof point.com/v2/url?u=https-3A_doi.org_10.1080_00218464.2019.1652602\&d=DwIFaQ\&c=vh6Fg FnduejNhPPD0fl_yRaSfZy8CWbWnIf4XJhSqx8\&r=7GjDei_PxQva2JNOfHbJQKIolTpKkGdW_ 4o9-CecCzX9fDPu7SrgsodpYCPByYz6\&m=Yis1G9yQzW2uLeNznmgMPv61ZefClMDYHHM FE5PNccU\&s=rdHWeu_g4jzDZgLD2BqN61cx5W0q1gC2ryPvk2i9oJA\&e=

Zhao J, Dai K, Liu C, Zheng G, Wang B, Liu C, Chen J, Shen C (2013) A comparison between strain sensing behaviors of carbon black/polypropylene and carbon nanotubes/polypropylene electrically conductive composites. Compos Part A-Appl S 48:129-136. https://doi.org/10.1016/j.compositesa. 2013.01.004

Publisher's Note Springer Nature remains neutral with regard to jurisdictional claims in published maps and institutional affiliations. 